\title{
MÍDIA, USO PÚBLICO E UNIDADES DE CONSERVAÇÃO: PROBLEMAS NO PARAÍSO
}

\section{RESUMO}

\author{
Douglas de Souza Pimentel ${ }^{1}$ \\ Fabíola Saporiti Angerami de Andrade ${ }^{2}$ \\ Daniela Custódio Talora ${ }^{3}$ \\ Teresa Cristina Magro ${ }^{4}$
}

\begin{abstract}
A hipótese dessa investigação é que as UCs são tratadas pela mídia como pequenos "paraísos", dentro de uma visão antropocêntrica centrada no uso público, sem uma reflexão mais profunda sobre os problemas inerentes à essa atividade. Este trabalho pretende avaliar como um veículo da mídia, a revista "Caminhos da Terra", considera o tema unidades de conservação nacionais, frente a essa hipótese. A metodologia utilizada foi a Análise de Conteúdo. Esperava-se que a visão de paraíso intocado fosse a predominante uma vez que a revista se preocupa também em vender seus espaços para propagandas relacionadas ao lazer e turismo. No entanto, essa hipótese não se confirmou, pois a visão prevalecente foi a técnicoconservacionista. Esses resultados podem estar expressando as recorrentes citações aos tipos de UCs, ao IBAMA e a Conservação, de maneira genérica. A falta de profundidade na abordagem destes assuntos acaba banalizando os problemas apresentados e generalizando soluções. Assim, tratar desses temas para o público em geral demanda uma postura mais crítica e embasada dos repórteres e isso parece não ocorreu para o período analisado desta revista.
\end{abstract}

Palavras-chave: Percepção Ambiental; Natureza; Mídia Impressa.

\section{ABSTRACT}

The hypothesis of this study is that protected areas are addressed in the media as small "paradises" within an anthropocentric overview focused on public use, with no debate on the problems arising from this activity. This paper aims to assess how the Brazilian magazine "Caminhos da Terra", considers the topic of national protected areas, related to this hypothesis. The methodology used was the Content Analysis. It was expected that the overview of pristine paradises would be predominant once the magazine is also concerned in selling spaces for advertisements related to leisure and tourism. Nevertheless, our hypothesis was not confirmed since the prevailing view was the technical-conservationist. These findings may be expressing the citations to the types of protected areas at Institutions like IBAMA and conservation, generically. Failure on having a depth approach of these issues ends up banalizing the issues raised from the tourism, and generalising solutions. So, addressing these issues for the public in general requires a more critical and well based view from the writers what did not happen in the analyzed period from this magazine.

Keywords: Environmental Perception; Nature; Press Media

\footnotetext{
${ }^{1}$ Prof. Adjunto UFF e UERJ. E-mail: douglasgeia@gmail.com

2 Dra em Conservação de Ecossistemas Florestais. E-mail: fabiola.saporiti@gmail.com

3 Profa. Dra do Depto. de Ciências Biológica da Universidade Estadual de Santa Cruz. E-mail: dani.talora@gmail.com

${ }^{4}$ Prof ${ }^{a}$ Dra., Departamento de Ciências Florestais, ESALQ/USP. E-mail: teresa.magro@usp.br
} 


\section{INTRODUÇÃO}

\section{Sociedade e Unidades de Conservação (UCs)}

Até o final do século XX havia alguma discussão sobre qual o modelo de área protegida havia sido adotado pelo Brasil. Essa discussão vem perdendo o vigor diante das prioridades que os especialistas em conservação ambiental tem se defrontado atualmente. $\mathrm{O}$ fundamento do debate se refere principalmente à permissão do uso direto dos recursos naturais por populações humanas em todas as categorias de manejo das UCs nacionais, ou seja, de uso sustentável e de proteção integral.

Segundo Gómez-Pompa e Kaus (2000), a capacidade científica para controlar o ambiente, aliada a percepção de pureza e equilíbrio da natureza trouxeram problemas para as políticas de manejo dos recursos naturais. Essa visão é frontalmente combatida por Terborgh e Van Schaik (2002), que advogam que a abertura dos parques para que as comunidades locais os usem sustentavelmente enfraqueceria o conceito de proteção integral da natureza. Complementarmente, outros defendem que os parques e reservas têm se mostrado os únicos instrumentos capazes de sustentar a biodiversidade, em áreas ameaçadas por atividades humanas (FONSECA, 2004).

Entretanto, o modelo de conservação em parques ainda carrega algumas contradições, principalmente relacionadas com a falta de ampla compreensão das diferentes formas dessa natureza socializada e transformada pela ação humana. Assim, os parques, tornam-se mais espaços conceituais do que físicos (WATSON, 2000; WATSON; LANDRES, 1999).

Assim, o debate transcende o ambiente acadêmico e a compreensão de como a sociedade percebe as áreas protegidas é fundamental para a construção de uma base efetiva para os esforços da conservação. Os projetos de conscientização, educação e, até mesmo, as parcerias para fins específicos necessitam de dados sobre como as UCs são idealizadas nos diferentes grupos de atores envolvidos em seu uso e proteção. Nesse sentido, o uso público dos parques assume uma enorme relevância, tanto no campo conceitual quanto na viabilização da construção de uma nova visão sobre a importância das UCs para a sociedade (PIMENTEL, MAGRO, SILVA-FILHO, 2011; PIMENTEL; MAGRO, 2012 a e b; PIMENTEL, 2015).

A mídia exerce relevante influência sobre a opinião pública, dessa forma, entender como esta aborda o tema das UCs, é primordial para o desenvolvimento de programas e de projetos relacionados à essas áreas protegidas nacionais. De acordo com SANTOS (2009) a mídia acaba exercendo o papel de potencializar uma temática de forma a torná-la pública e consequentemente outras pessoas acabam sendo convidadas a participar das discussões. Além disso, a discussão sobre a conservação ambiental deixou de ser pauta apenas dos encontros científicos e acadêmicos, e ganhou espaço na programação da televisão, nos jornais impressos e nas revistas. Nesse contexto, as UCs que recebem grande impulso pelo turismo e pela busca de aventura, também ganharam destaque na mídia nacional. Logo, o uso público dos parques pode trazer uma nova sensibilização para a conservação da natureza, mas também o perigo da degradação se não for planejado e organizado. 
Pode-se considerar ainda que a imprensa tem forte impacto, não só sobre o público em geral, mas também sobre os tomadores de decisão, responsáveis pelo manejo das UCs (KARAM et al, 2002). A mídia pode ter um caráter informativo/educativo ou comercial, principalmente para algumas categorias de UCs, como os parques nacionais altamente procurados pelas companhias de turismo. A conscientização da sociedade quanto à realidade das áreas protegidas nacionais é absolutamente necessária, pois, pressões adversas atuam de várias formas sobre essas áreas.

Guedes (2000) considera que a construção das questões ambientais se daria numa perspectiva tecnocêntrica - a natureza como fonte de recursos e valorada somente como um instrumento para atender às necessidades humanas. $\mathrm{O}$ autor fez um levantamento em diferentes jornais de circulação nacional e local no Brasil com o objetivo de construir um quadro das características da cobertura de assuntos ambientais nesses veículos. Os resultados mostraram que a cobertura sobre as reservas de áreas para a proteção da natureza representou apenas $6,4 \%$ do total. Apesar de uma visão ecocêntrica ter sido observada - que considera os valores intrínsecos da natureza, a visão prevalecente foi a tecnocêntrica. A autora considerou ainda que a mídia brasileira demorou a prestar atenção nas questões ambientais. Assim, a mídia teria mais acompanhado do que iniciado à preocupação com o meio ambiente no Brasil.

A partir de uma pesquisa em sumários correntes, realizada por uma empresa particular para a rede PRO-UC, Karam e colaboradores (2002) analisaram reportagens dos principais jornais impressos no país, além de oito veículos de comunicação disponíveis na internet, com o objetivo de avaliar de que forma as UCs estavam sendo tratadas pela imprensa nacional escrita em quatro aspectos: a quantificação das matérias; a análise da causa da inserção das mesmas; o nível de detalhamento dos textos; e a análise quali-quantitativa das categorias de manejo contempladas pelas matérias. Os autores observaram que a categoria parque nacional (PARNA) foi a mais citada de forma isolada em todas as matérias analisadas e a categoria reserva biológica (REBIO) foi citada em apenas 3\% das reportagens. Por razão do fechamento da Estrada do Colono no PARNA de Iguaçu o número de citações sobre parques aumentou significativamente e o foco se voltou para os problemas sociais relacionados, em detrimento das questões de conservação ambiental. Os autores destacaram ainda a falta de conhecimento por parte dos jornalistas sobre as questões ambientais e UCs. Especificamente "os textos demonstraram desconhecimento dos jornalistas acerca da(s) categoria(s) em questão, muitas vezes dando-se o mesmo tratamento para diferentes categorias, podendo gerar má interpretação da informação por parte do leitor” (KARAM et al, 2002. p. 668).

A hipótese dessa investigação é que as UCs são tratadas pela mídia como pequenos "paraísos". Dentro de uma visão antropocêntrica centrada no uso, sem uma reflexão mais profunda sobre os problemas inerentes à sua exploração. Acredita-se também que a categoria de UC nem sempre seja citado de maneira correta dentro das reportagens. Nesse sentido, o presente artigo pretende avaliar como um veículo da mídia, a revista "Caminhos da Terra", considera o tema unidades de conservação nacionais, frente a essa hipótese. 


\section{MATERIAL E MÉTODOS}

A publicação escolhida para essa investigação foi a revista "Caminhos da Terra", de periodicidade mensal cuja temática principal é a relação do homem com o meio ambiente e sua história, por meio do turismo.

A metodologia utilizada foi a Análise de Conteúdo de acordo com Bardin (1977). O corpus documental constituiu-se em 35 números da revista, abrangendo os anos de 2001, 2002 e $2003^{5}$. Foram escolhidas as reportagens principais da revista, e não aquelas relacionadas com as colunas regulares, presentes em todos os números. Todas as reportagens que faziam referência a UCs presentes no SNUC foram selecionadas.

Procedeu-se uma "leitura flutuante" para o estabelecimento do primeiro contato com os textos e levantamento das primeiras impressões, orientando assim a formulação dos indicadores da codificação do material. Com base nessa leitura, as categorias selecionadas foram: conflito social, visão técnico-conservacionista, visão utilitária e visão de paraíso intocado. Para cada categoria, uma série de palavras indicadoras foi elaborada e o número de vezes que as mesmas apareciam no texto foi contado e anotado nas categorias correspondentes em fichas de análise.

A frequência total de cada categoria foi analisada para cada ano com o intuito de se avaliar o perfil e as mudanças da visão da revista em relação às UCs nacionais.

\section{RESULTADOS E DISCUSSÃO}

Esperava-se que a visão de paraíso intocado fosse a predominante uma vez que a revista se preocupa também em vender espaços da revista para propagandas relacionadas ao lazer e turismo. No entanto, essa hipótese não se confirmou, pois a visão prevalecente foi a técnico-conservacionista nos três anos analisados (Tabela I), e é possível que este resultado tenha sido obtido por um viés derivado da escolha de algumas palavras recorrentemente citadas, como, por exemplo, a categoria de UC.

Outro dado interessante é que a visão de paraíso não oscilou tanto nos anos quanto a visão utilitária, que teve um pico em 2001 (Figura 1). O aumento marcante da visão de conflito no ano de 2003 também deve ser destacado e talvez esse fato seja decorrente da mudança editorial da revista ocorrida em 2003.

\footnotetext{
${ }^{5}$ A edição de abril de 2002 não fez parte da análise por não ter sido localizada.
} 
Tabela I - Números absolutos da contagem das palavras por categorias e por ano, a partir da análise das 35 edições da revista "Caminhos da Terra", referentes aos anos de 2001 a 2003.

\begin{tabular}{|l|c|c|c|c|}
\hline \multicolumn{1}{|c|}{ Anos } & $\mathbf{2 0 0 1}$ & $\mathbf{2 0 0 2}$ & $\mathbf{2 0 0 3}$ & GERAL \\
\hline Conflito social & 29 & 31 & 132 & 221 \\
\hline Técnico-conservacionista & 244 & 240 & 294 & 778 \\
\hline Utilitária & 196 & 76 & 115 & 387 \\
\hline Paraíso intocado & 124 & 136 & 135 & 395 \\
\hline TOTAL & $\mathbf{5 9 3}$ & $\mathbf{4 8 3}$ & $\mathbf{6 9 2}$ & $\mathbf{1 7 8 1}$ \\
\hline
\end{tabular}

Figura 01 - Gráfico de frequências das categorias por ano, a partir da análise das 35 edições da revista "Caminhos da terra", referentes aos anos de 2001 a 2003.

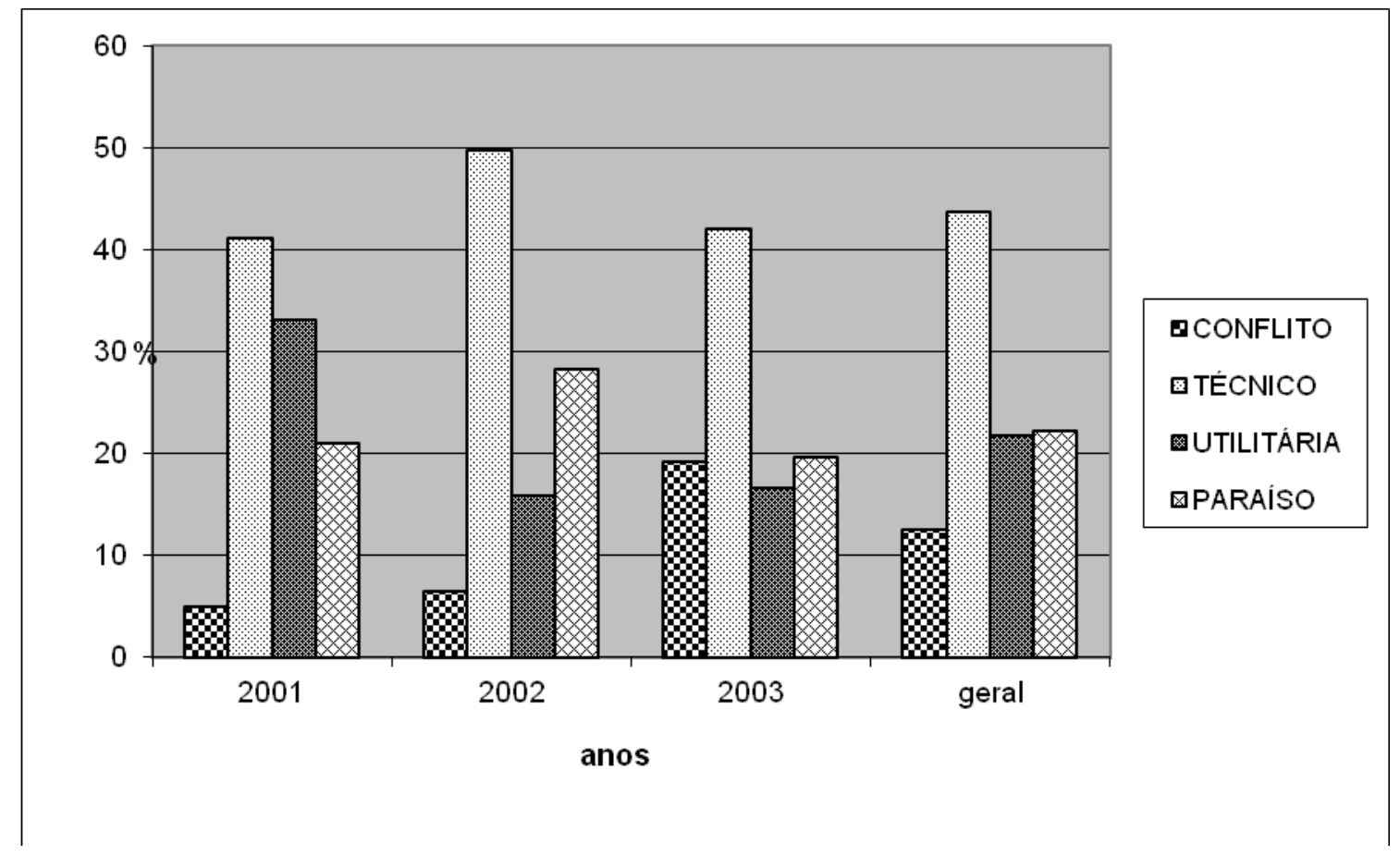

Mesmo tendo prevalecido a visão técnico-conservacionista nos resultados, o enfoque dado a essas questões do meio natural é superficial. Os verbetes "conservação", "proteção" e "preservação" são usados corriqueiramente e sem distinção conceitual. Há também o uso indevido de categorias de UCs, como o uso dos termos independentemente da categoria à que se fazia referência. O uso inapropriado de "área de proteção" sem determinar a categoria de UC também foi observado. 
Por outro lado a revista tem um papel importante em mostrar que o Brasil é muito mais do que os locais tradicionalmente visitados e/ou destacados pela mídia mais tradicionalista, e mesmo com problemas técnicos nos textos, é um veículo de difusão de problemas e de propostas de conservação para o país, sendo que na maioria dos números analisados, pelo menos uma das reportagens principais abordava temas relacionados às UCs, enquanto Guedes (2000) encontrou apenas 6,4\% das reportagens analisadas em jornais versando sobre áreas naturais protegidas.

Nos anos de 2001 e 2002, não foram observadas grandes disparidades entre os textos lidos (Figura 1). Nenhum texto teve a predominância da visão de conflito neste período analisado (4,89\% em 2001 e 6,41\% em 2002). Em 2003, apesar da categoria "visão Técnicoconservacionista" representar cerca de $40 \%$ das citações das palavras indicadoras, a maioria delas faz referências às categorias das UCs $(30,61 \%)$, em alguns casos, erradas, ou a atividade de conservação e órgãos governamentais $(10,54 \%)$, especificamente o IBAMA ${ }^{6}$ ou aos pesquisadores e outras pessoas que atuam nas UCs $(23,12 \%)$, talvez para dar um caráter mais embasado às reportagens.

No ano de 2001, as palavras relacionadas ao contexto de conflito social se referiam à história de antigos conflitos ou mostravam que o local foi cenário de algum fato relevante da História do Brasil, como a passagem da Coluna Prestes por Costa Rica próxima ao Parque Nacional de Emas. Apenas na reportagem "Um parque renasce", a questão atual de conflito é apontada, por meio das ações sumárias da arqueóloga Niède Guidon, mentora do Parque Nacional da Serra da Capivara no Piauí. Essa mesma reportagem se destaca por ter tido um número alto de citações na visão técnico-conservacionista. Nenhuma outra reportagem destacou tão enfaticamente que a área tratada era um parque nacional.

Na análise do ano de 2002, a reportagem sobre a Serra das Confusões, mostra conflitos relacionados ao uso público e depredação da área. Vale lembrar que também nesta reportagem predomina a visão conservacionista (72,4\% dos termos levantados), sendo que se enfatiza o termo "Parque Nacional" várias vezes no texto. Mesmo assim, o autor se equivoca quando chama, em alguns momentos, a área de "reserva". Também neste texto o verbete parque foi muito utilizado.

A visão técnica, predominante na revista, especialmente nos anos 2001 e 2002, também pode ser destacada em várias outras reportagens. Em 2001, por exemplo, "Um anjo no paraíso" mostra a abnegação de uma professora trabalhando com comunidades próximas ao Parque Estadual da Serra do Mar (PESM) e ao PARNA da Serra da Bocaina. Em "Estranhos no ninho" o autor retrata a ação de profissionais no resgate de espécies animais silvestres que aparecem na cidade de São Paulo e são conduzidas para área naturais como o Parque Estadual da Serra da Cantareira. Já em "O Brasil em estado bruto" que tenta mostrar um estado do Amapá conservacionista, valorizador de suas tradições e de sua diversidade biológica e cultural, mas deixa pontos controversos, já com visão utilitarista:

\footnotetext{
${ }^{6}$ Até 2007, quando foi criado o Instituto Chico Mendes de Conservação da Biodiversidade - ICMBio (em 28/08/ 2007), o IBAMA era o órgão federal responsável pela gestão das UCs .
} 
Atento a essa riqueza, o Estado está investindo no que é sua vocação natural: o Ecoturismo. O melhor exemplo é a Escola Bosque, fundada em 1998 (...) 540 alunos (...) estudam a fauna, a flora, os solos, os rios, recebendo formação técnica em ciência ambiental, além do ecoturismo.

Ainda em 2001, o único texto que traz o verbete "plano de manejo" se intitula "No coração do abismo", discorrendo sobre os PARNA de Aparados da Serra e da Serra Geral, e mostra as mudanças com a implantação dos mesmos "depois do novo plano de manejo, parte do primeiro (cânion) foi interditada", a reportagem também tenta mostrar um forte envolvimento comunitário em torno dos parques, citando várias ações da comunidade em termos de conservação.

No ano de 2002 o texto "O destino do Velho Chico" dá uma visão histórica sobre o uso e ocupação em torno deste importante rio brasileiro, alertando sobre sua péssima conservação. Problemas como poluição, sobrepesca e desmatamento são destacados em vários momentos, como pode ser observado no trecho que se segue: "Se as águas estão envenenadas, algo não muito mais alentador pode ser dito em relação às terras situadas nas imediações do rio. As queimadas, que aceleram o processo de desertificação, vêm pondo em risco numerosas espécies [...]". A reportagem intitulada "Costa dos Corais" também aponta os problemas relacionados à conservação da área, que atualmente não tem sido mais tão generosa para a pesca, estando sendo utilizada principalmente no turismo, devido à facilidade de acesso e às suas belezas naturais. O autor destaca o conflito que ele denomina de "desafio moderno de equacionar a sobrevivência dos nativos, a voracidade dos visitantes e a resistência dos ambientes".

Nos textos "A hora do Lobo" (junho de 2002) e "Peixe-boi: uma chance para o gigante das águas" (janeiro de 2002) o enfoque conservacionista é centrado na preservação das espécies (lobo guará e peixe-boi, respectivamente). A preocupação com estas espécies ameaçadas pode ser sentida no seguinte trecho, sobre o peixe-boi:

[...] a caça não é mais a grande ameaça dos peixes-boi. A expansão imobiliária, a poluição dos estuários e as fazendas de camarões, que destroem manguezais, são as atuais agressões à espécie. As fêmeas [...] estão parindo em mar aberto, uma vez que não encontram abrigo nos mangues [...] os filhotes perdem-se em meio às ondas e acabam encalhados na praia, onde morrem.

Percebe-se frequentemente o convite a se visitar o "paraíso" como nas citações lidas em 2001: "o cerrado se enche de luzes e tudo se torna um grande céu estrelado" ou sobre o PARNA de Emas; "As várias paisagens da região são maravilhosas." Sobre o PARNA do Pico da Neblina o autor destaca: "Enormes jardins de bromélias, fiapos de fonte d’água entre as pedras, várias espécies de orquídeas, riachos de água mineral e a opulência das serras rasgando as nuvens parecem nos empurrar para cima”. Normalmente no final dos textos são colocadas frases de apelo estético que funcionam como esses convites. O mesmo se repete no ano de 2002, como pode ser observado na reportagem sobre a Chapada Diamantina que se 
inicia com as frases: "A Bahia tem um coração de ouro. Enorme, pulsante e generoso como poucos [...] Incansável, bombeia água de $90 \%$ dos rios baianos, fornece pedras preciosas e ainda recebe 80 mil visitantes por ano." E finaliza como transcrito a seguir: "[...] há muito mais tesouros enterrados no coração dourado da Bahia do que nós pudemos imaginar. E nem todos são pedras preciosas". Estas citações abrem e fecham um texto romantizado, que versa principalmente sobre cenários, cachoeiras e outras belezas naturais da Chapada.

Outro texto em que se destaca a visão de paraíso (59\%), é "Labirinto de areia: a estonteante mistura de dunas e lagoas nos Lençóis maranhenses", como pode ser visto pelo próprio título, e nos trechos citados a seguir: “[...] as dunas aparecem de repente. Seus contornos suaves se abaulados represam lagoas em forma de enguias e asas-delta."

Entre as visões técnico-conservacionista e utilitária há um jogo interessante, algumas reportagens apresentam-nas de forma explícita, praticamente zerando as referências de uma delas. Por outro lado, às vezes aparece um equilíbrio entre as mesmas. O texto "Verdes \& verdinhas" como o próprio título indica, a profusão de palavras de visão utilitarista é espantosa, pois aborda a busca das empresas pelo "marketing verde". Em outra reportagem cujo título é "Parati: a joia da coroa" a visão utilitária também é bastante predominante, mas, nesse caso, a justificativa está no enfoque turístico, de obtenção de renda e trabalho por meio deste: "o turismo tornou-se um dos principais combustíveis da economia, estimulando o aparecimento de hotéis, pousadas, condomínios e marinas. Ex-pescadores oferecem passeios de barco [...]". Ainda sobre o "Parque Nacional da Serra da Bocaina: 100.000 hectares de área, um show de Mata Atlântica". Também o texto sobre a instalação do PARNA de Jericoacoara tem uma abordagem bastante utilitarista: “[...] um garoto de 14 anos, trabalhando como guia num feriadão, chega a faturar mais de 100 reais. Já uma canoa que vai ao mar, num dia ruim, permite um faturamento não superior a 30 reais, que deve ser compartilhado por quatro pescadores".

No ano de 2002, o texto sobre a Chapada dos Veadeiros, intitulado "Maior Abandonado", se alternam descrições de um paraíso: "Os cenários que se descortinam ao final de cada trecho vencido a pé, de carro ou a nado são espetaculares." com a preocupação em relação à conservação da área, especialmente pelo total de famílias - 400 - que vivem dentro da área do parque:

Além de tornar Parque Nacional áreas tradicionalmente utilizadas pelos pequenos fazendeiros para alimentar os bois e ainda hoje queimadas para renovar o pasto, o governo federal não tem a menor ideia do que fazer nem para onde enviar as pessoas eventualmente retiradas da área.

Esta visão está bem destacada no texto quando se discute o aumento da área do parque, feito sem estudos prévios, para conseguir o título internacional de "Patrimônio Natural da Humanidade".

Já em 2003, uma estrutura interessante das reportagens pôde ser percebida, diferenciando estas reportagens daquelas dos anos anteriormente analisados. De um modo geral os textos começam a falar sobre a beleza do lugar, às vezes colocando alguns aspetos 
históricos. $\mathrm{O}$ isolamento das comunidades locais é frequentemente destacado. Na sequência, fazem referência à UC e então começam a aparecer os conflitos. A solução proposta, geralmente refere-se ao aspecto financeiro e de "uso sustentável" do patrimônio ambiental. Quando as frequências gerais das categorias conflito (19,07\%); utilitária (16,61\%) e paraíso $(19,50 \%)$ são analisadas (Figura 1), observa-se que realmente aproximadamente o mesmo peso foi dado para as três visões. $\mathrm{Na}$ reportagem "A vida ao sabor dos ventos" (novembro/2003) de Cindy Wilk, o texto refere-se à beleza e isolamento do lugar ressaltando que as pessoas estão submissas aos "humores" de uma "natureza inquieta" e personalizada que "gosta" de "mudar a paisagem como quem troca um sofá ou uma mesa de lugar". Na sequência, o Parque Nacional dos Lençóis Maranhenses é citado, e o contraponto utilizado cita que os:

[...] moradores de Mandacaru, como em todos os outros lugares da região, sempre viveram da pesca. Hoje muitos trabalham nas proximidades de Caburé, na margem oposta. A troca de atividade profissional não é o mais estranho [...].

A solução apresentada para as comunidades é o turismo porque "Essa cidade de 50.000 habitantes sempre viveu do mar, mas a pesca predatória acabou com os peixes...". Nesse ponto ressalta-se que a cidade acabara de ganhar um "luxuoso resort". Pode-se intuir que a população local destruiu os recursos naturais e a presença do Parque não impediu que isso acontecesse. Mas agora ele funcionaria como um pólo atrativo da única alternativa viável: o "resort". Não se discute a mudança da cultura local e nem como as pessoas estão se inserindo na modificada economia. Existem referências aos problemas causados pelo turismo de massa no litoral, como a especulação imobiliária, que acaba por expulsar as comunidades locais (BURSZTYN, 2001).

A tônica se repete na reportagem "Paraíba - as praias esquecidas" (Dezembro/2003), de Walter Pessoa. O texto destaca a beleza e ausência de pessoas, como o atrativo principal do local e cita que historicamente, esse fato seria explicado pelo antagonismo dos índios Potiguaras, o "povo guerreiro" que resguardou esse pedaço do litoral brasileiro da ocupação maciça. Faz-se então referência à Área de Proteção Ambiental do Mamanguape e os problemas começam à aparecer pois "O objetivo do estudo (na APA) é controlar a pesca indiscriminada do pequeno animal (camarão), definindo estratégias para comercializá-lo sem causar um grave desarranjo biológico" (grifos e observações nossas). O interessante é que na APA há um projeto de introdução do peixe boi marinho no ambiente natural, que o texto menciona, mas não faz referência ao projeto desenvolvido com as famílias de pescadores que confeccionam artesanato e bichos de pelúcia em contrapartida à pesca desse animal. Esses mamíferos são tratados com o intrigante termo de "hóspedes aquáticos". Resta saber quanto tempo eles ficarão "hospedados" no local. Mais uma vez a solução implementada relacionase, "segundo orientação e acompanhamento dos técnicos do IBAMA" à:

[...] coleta de ostras e frutos silvestres e da pesca controlada do caranguejo e do camarão, numa bem sucedida amostra de algo 
próximo a uma reserva extrativista onde se respeita ao mesmo tempo conservação da natureza e economia local.

Mas uma vez faz-se apologia à uma UC de uso sustentável, talvez por que as de uso indireto não respeitam a "economia local". A não ser que ela seja aberta ao "ecoturismo". Na reportagem "Imperatriz das Águas" (Fevereiro/2003) de Claudia Carmelo, o Parque Estadual da Chapada do Tabuleiro é apresentado como "o grande tesouro da região." No entanto, ressalta-se que o Parque foi "criado em 1975 e sua implantação ainda não saiu do papel". Logicamente a ausência do poder público na gestão da UC se traduz na frase seguinte: "Muitas das possibilidades de ecoturismo na região ficam dentro do Parque". Essas UCs precisam de um zoneamento das formas de uso, sem o qual as atividades de turismo podem ser altamente degradadoras. Sobre essa lacuna se propõe a construção de toda a atividade turística da região, que o Parque não limita e ordena por não ter sido efetivamente implantado. Nesse ponto podemos supor se esse interesse imediatista vai permitir que o parque "saia do papel”.

Essa visão econômica parece ser a ideia central das reportagens de Klester Cavalcanti que em algumas reportagens usa o termo "boa notícia" ou "boas novas", para expressar o seu otimismo com relação ao futuro das UCs: Em "Mata Atlântica - nem tudo está perdido" (outubro/2003) o aspecto da destruição do Ecossistema não poderia ser omitido, mas:

[...] as boas notícias começam a aparecer. A mais animadora delas é que a Mata Atlântica está se recuperando [...] num país em que engenheiros, advogados e médicos se espremem em filas quilométricas disputando uma vaga de gari da prefeitura do Rio de Janeiro, para ganhar 600 reais por mês, é no mínimo surpreendente encontrar um caiçara, que nunca saiu do mangue, com trabalho fixo e um salário de fazer inveja a muitos brasileiros (750 reais).

O autor conclui então que "a mudança na vida de Mário (o caiçara retratado na reportagem) reflete perfeitamente o que está acontecendo com a Mata Atlântica” (grifo nosso). O teor da reportagem gira em torno de investimento de ONGs em projetos de alternativas econômicas de exploração dos recursos naturais pelo extrativismo, caso do afortunado Mário, ou pelo ecoturismo.

Na reportagem "O Insólito Pantanal Amazônico" (Fevereiro/2003), a UC tratada é a Reserva de Desenvolvimento Sustentável do Piranha, da categoria de uso sustentável, portanto. A estrutura do texto repete-se na visão de natureza única e os problemas referem-se ao "sumiço de espécies" que

[...] foi provocado por pescadores e caçadores que até recentemente invadiam a região. [...] Passar o final de semana agredindo a fauna e bagunçando o equilíbrio ecológico era um dos programas preferidos dos burgueses de Manaus [...] as boas notícias são os primeiros resultados da criação da Reserva de Desenvolvimento Sustentável do Piranha [...] 
Sustentando que "a área já está preservada. O desafio agora é atrair investimentos (para projetos sociais e científicos)".

Esse texto é apresentado como uma chamada e o que está entre parênteses aparece em letra muito menor que a primeira frase. Talvez isso denote a importância dada aos investimentos sociais e em pesquisa.

Ainda:

A ideia básica - utilizar os recursos naturais de maneira sustentável está firmada na mentalidade dos ribeirinhos. É deles a responsabilidade (!) de fiscalizar os rios e as matas, impedindo que invasores agridam a fauna e a flora. Foi também de algumas das quarenta famílias que vivem na reserva que saíram os funcionários que irão trabalhar no único hotel da região, o Hotel Lago Piranha, que está em reforma e deve ser aberto em agosto. Cozinheiras, atendentes, arrumadeiras e guias foram selecionados nas comunidades ribeirinhas." (negrito e observações nossas).

Observando-se essas reportagens pode-se deduzir duas questões: a primeira refere-se ao fato de como as reservas de uso indireto estão sendo tratadas por essa visão economicista e talvez relacionar esse fato com a constatação de que a maioria realmente não têm planos de manejo, que na verdade atrapalhariam essa relação utilitarista, ao limitar e modificar as formas de uso do espaço. A segunda refere-se a como as ditas, comunidades locais, estão sendo inseridas economicamente nesse processo.

"Boas novas do cerrado" (Maio/2003) é a única reportagem em que esse autor associa a presença de pesquisadores em uma UC a uma boa notícia, nesse caso, o Parque Nacional das Emas. Nesse caso, também destaca o zelo de alguns fazendeiros em proteger a região, apesar de paradoxalmente mostrar preocupação com o Parque estar completamente cercado por fazendas e sofrer com os efeitos dos agrotóxicos.

A questão desse embate com fazendeiros também é destacada na reportagem com o sugestivo título: "De quem é este Parque?" (junho/2003) de Cristina Degam e Gustavo Mansur, que falam do Parque Nacional da Lagoa do Peixe, no Rio Grande do Sul, destacando que "O Parque está para completar 17 anos e tudo isso (preservação, pesquisa, recreação) não passa de ficção". Isto é, as funções básicas da UC não estão sendo cumpridas, pela omissão do poder público em assumir o ônus financeiro da conservação, mas também "[...] como explicar as mais de 150 famílias que vivem nas proximidades da lagoa que as terras onde seus antepassados viviam há mais de 100 anos agora eram Parque Nacional" que surge como "uma ameaça ao povo da região". Interessante agora é destacar que algumas das famílias são de fazendeiros, com maior inserção econômica. Nesse caso, a reportagem parece revelar um maior antagonismo com a UC em que aparecem em igual proporção as palavras briga, embate, luta e ilegal. A mesma preocupação não aparece na reportagem "Uruçuí-Una - O coração do cerrado", sobre a Estação Ecológica de mesmo nome, que destaca que "alguns 
pesquisadores consideram obrigatória a retirada das famílias que vivem na área da reserva. Para eles, a preservação da fauna e da flora da região não pode ser assegurada enquanto as comunidades viverem ali." Essas comunidades pobres também já estavam presentes na região antes da criação da UC que, aliás, é erroneamente tratada como reserva ao longo de todo o texto.

\section{CONSIDERAÇÕES FINAIS}

Apesar da visão técnico-conservacionista ter se destacado das demais, os resultados podem estar expressando as recorrentes citações aos tipos de UCs, ao IBAMA e a Conservação, de maneira genérica. Talvez também, se queira dar um caráter mais embasado tecnicamente às reportagens. No entanto, esse objetivo é fracamente alcançado, uma vez que se excluída essa visão, o que sobra é a visão do Paraíso utilizada para "vender" o turismo nas localidades.

No ano de 2003, aparece com igual importância a visão de conflito, que no caso parece substanciar o turismo e outras formas de uso como a solução para dirimi-los. Atribuise a alteração no teor dessas reportagens a uma mudança ocorrida no corpo editorial da revista.

Embora se acreditasse que a visão de paraíso intocado fosse ser a de maior destaque, a visão técnico-científica foi a mais evidente conforme já citado, mas o conflito e a visão utilitária se fizeram presentes de forma marcante em outras reportagens. A visão idílica, já muito difundida pela mídia nas décadas anteriores, parece estar sendo substituída por uma mais realista, que enfoca problemas e tenta apontar o uso das áreas protegidas, especialmente o turístico, como uma saída econômica, social e ecologicamente viável. Entretanto, a falta de profundidade na abordagem destes assuntos acaba banalizando os problemas apresentados, e generalizando soluções para áreas muito distintas, e com tipos de uso diferentes, conforme previsto no Sistema Nacional de Unidades de Conservação (SNUC).

A confusão com a nomenclatura das UCs, bem como o uso inadequado de termos como "conservação" e "preservação" pode levar ainda a interpretações errôneas quanto ao tipo de uso em cada localidade, prejudicando o entendimento das categorias de UCs (proteção integral x uso sustentável). As questões relacionadas às UCs, geralmente envolvem problemas complexos que transcendem a visão ecológica. Assim, tratar desses assuntos demanda uma postura mais crítica e embasada dos repórteres e isso parece não estar ocorrendo na revista analisada.

\section{REFERÊNCIAS BILIOGRÁFICAS}

BARDIN, L. Análise de Conteúdo. Edições 70. 1977. 229 p.

BURSZTYN, I. Especulação imobiliária no litoral cearense. Caderno virtual de turismo. Rio de Janeiro. Julho 2001. Disponível em: <http://www.ivtrj.net/caderno/anteriores/7/especulacao /especulacao1.htm>. 
FONSECA, G.A.B. The everlasting role of protected areas in biodiversity conservation. In: MILANO, M.S.; TAKAHASHI, L.Y.; NUNES, M.L (Org.): Unidades de Conservação: atualidades e tendências 2004. Curitiba: Fundação O Boticário de Proteção à Natureza. 2004. $208 \mathrm{p}$.

GÓMEZ-POMPA, A. \& KAUS, A. Domesticando o mito da natureza selvagem. In: DIEGUES, A.C. (Org.). Etnoconservação. Novos Rumos para Conservação da Natureza. São Paulo: HUCITEC. 2000. p.125 - 147.

GUEDES, O. Environmental Issues In The Brazilian Press. GAZETTE, v.62 n.6 p.537-554. 2000.

KARAN, G.Z.; ZELLER, R.H.; CONEGLIAN, S.J. A mídia e a conservação da natureza: uma análise da relação entre a imprensa brasileira e as unidades de conservação. In: CONGRESSO BRASILEIRO DE UNIDADES DE CONSERVAÇÃO. 3. Anais... Fortaleza: Rede Nacional Pro Unidades de Conservação, Fundação O Boticário de Proteção à Natureza, Associação Caatinga. v.1, p.661-670. 2002.

PIMENTEL, Douglas de Souza; MAGRO, Teresa Cristina. Diferentes dimensões da Educação Ambiental para a inserção social de parques. Revista Brasileira de Educação Ambiental. v.7, n.2. p. 44-50, 2012a.

. Múltiplos olhares, muitas imagens: o Manejo de Parques com base na complexidade social. Geographia. P.92-113. 2012 b.

PIMENTEL, Douglas de Souza; MAGRO, Teresa Cristina; SILVA-FILHO. Imagens da conservação: Em busca do apoio público para a gestão de unidades de conservação. Teoria e Sociedade. n.19. p.144-169. 2011.

PIMENTEL, Douglas de Souza. Parcerias para a gestão do uso público e parques. In. Vallejo, L.R. Pimentel, D.S. e Montezuma, R.C. (orgs.). Uso Público em Unidades de Conservação. Planejamento, turismo, lazer e impactos. p.21-29. 2015.

SANTOS, Leonardo Bis dos. Trilhas da política ambiental: conflitos, agendas e criação de unidades de conservação. Ambiente \& Sociedade, Campinas v. XII, n. 1, p. 133-150. 2009

TERBORGH, J. \& VAN SCHAIK, C. Por que o mundo necessita de parques? In: TERBORGH, J.; VAN SCHAIK, C.; DAVENPORT, L.; RAO, M. (Org.). Tornando os Parques Eficientes: estratégias para a conservação da natureza nos trópicos. Curitiba: UFPR; Fundação O Boticário de proteção à Natureza. 2002. p. 25-36.

WATSON, A.E. \& LANDRES, P. Changing wilderness values. In: CORDELL, H. K. (Org.). Outdoor recreation in American life: a national assessment of demand and supply trends. Champaign, IL: Sagamore ,1999.p. 384-388.

WATSON, A.E. Wilderness use in the year 2000: societal changes that influence human relationships with wilderness. USDA forest service proceedings RMRS, v.4, p.53-60, 2000. 